\title{
Development of a Documentation Rubric and Assessment of Pharmacists' Competency for Documentation in the Patient Health Record
}

\author{
Brittany Baranski, Jennifer Bolt, Lori Albers, Rabiah Siddiqui, Ali Bell, and William Semchuk
}

\begin{abstract}
Background: Documentation of information in the health record by pharmacists is vital to patient care. Failure to document, or failure to document appropriately, may have negative effects on patients.

Objectives: The primary objective was to determine pharmacists' competency in 18 elements of chart note documentation at 2 tertiary care centres and 1 rehabilitation centre. The secondary objectives were to quantify the number of episodes of documentation by pharmacists, to characterize the clinical activities associated with this documentation, and to determine whether there were differences in level of competency according to years of hospital experience, additional clinical training, and note type.
\end{abstract}

Methods: This study used prospective audit methodology. Notes documented during a 6-week study period (February to April 2015) were assessed using a rubric specifically created to evaluate 18 of the essential elements of documentation, as defined by the Canadian Society of Hospital Pharmacists. Four of the elements of chart note documentation were assessed on a yes/no basis, and Bloom's taxonomy was used to define the level of competency for the other 14 elements. Values were assigned to each level and were then used to calculate mean scores.

Results: A total of 115 pharmacist notes, created by 29 of the 35 pharmacists included in the study, were assessed. The mean competency score per pharmacist was 2.2 (standard deviation [SD] 0.3; maximum score 3). Elements of documentation with the highest level of competency were diplomatic tone, conciseness, and clarity; elements with the lowest level of competency were medication list, note title, monitoring, and drugrelated problem statements. The most frequent note types concerned drug-related problems (50 [43\%]), pharmacokinetics (25 [22\%]), and patient education (19 [17\%]). Levels of competency were highest for notes related to patient education (mean 2.4, SD 0.2) and lowest for notes concerning drug-related problems (mean 2.1, SD 0.3) and notes providing clarification (mean 2.1, SD 0.3). The level of competency was not significantly affected by additional clinical training or years of hospital experience.

Conclusions: Pharmacists in this study documented concisely, clearly, and in a diplomatic tone; however, there was room for improvement in the frequency and elements of chart note documentation in the patient health record.

\section{RÉSUMÉ}

Contexte : La consignation d'information par les pharmaciens dans les dossiers de santé est essentielle aux soins des patients. Négliger de consigner l'information ou le faire inadéquatement peut avoir des effets négatifs pour les patients.

Objectifs : L'objectif principal était de déterminer le niveau de compétence des pharmaciens en ce qui concerne 18 éléments de consignation aux dossiers médicaux de patients dans deux établissements de soins tertiaires et dans un établissement de réadaptation. Les objectifs secondaires étaient de quantifier le nombre de cas de consignation par les pharmaciens, d'offrir un portrait des activités cliniques associées à cette prise de notes et de déterminer s'il y avait des différences quant au niveau de compétence selon le nombre d'années d'expérience en hôpital, la formation clinique supplémentaire et le type de notes.

Méthodes : La présente étude a employé l'audit prospectif comme méthodologie. Les notes consignées durant une période de 6 semaines (de février à avril 2015) ont été jugées à l'aide d'une grille conçue spécialement pour évaluer 18 des éléments essentiels de la prise de notes tels qu'ils sont définis par la Société canadienne des pharmaciens d'hôpitaux. Une évaluation dichotomique (soit oui soit non) a été utilisée pour quatre des éléments de la prise de notes et la taxonomie de Bloom a servi à définir le niveau de compétence pour les 14 autres éléments. Des valeurs ont été attribuées à chaque niveau et ont ensuite été utilisées pour calculer les scores moyens.

Résultats : Au total, 115 notes rédigées par 29 des 35 pharmaciens visés par l'étude ont été analysées. Le score moyen de compétence par pharmacien était de 2,2 (écart-type de 0,3; score maximum de 3). Les éléments de la prise de notes présentant le niveau de compétence le plus élevé étaient : le ton diplomatique, la concision et la clarté. Les éléments affichant le plus bas niveau de compétence étaient : la liste des médicaments, le titre de la note, le suivi et l'énonciation des problèmes liés à la pharmacothérapie. Les types de notes les plus fréquents traitaient : de problèmes liés à la pharmacothérapie (50 [43\%]), de la pharmacocinétique (25 [22\%]) et des conseils aux patients (19 [17\%]). Les niveaux de compétence étaient plus élevés pour les notes à propos des conseils aux patients (moyenne de 2,4 , écart-type de 0,2 ) et les niveaux étaient plus faibles pour les notes concernant les problèmes liés à la pharmacothérapie (moyenne de 2,1 , écart-type de 0,3 ) et celles fournissant un éclaircissement (moyenne de 2,1, écart-type de 0.3). Le niveau de compétence n'était pas 
Keywords: pharmacist, documentation, competency assessment

\section{Can J Hosp Pharm. 2017;70(6):423-9}

significativement influencé par une formation clinique supplémentaire ou les années d'expérience en hôpital.

Conclusion : Les pharmaciens évalués dans la présente étude consignaient leurs notes de façon concise et claire sur un ton diplomatique. Par contre, il y avait lieu d'améliorer la fréquence et les éléments des notes consignées dans les dossiers médicaux des patients.

Mots clés : pharmacien, prise de notes, évaluation de la compétence

\section{INTRODUCTION}

$\mathrm{D}$ ocumentation in the health record is vital to continuity of safe patient care. ${ }^{1}$ Pharmacists are expected to collaborate and communicate with other health care providers, and the patient health record is an important medium for such professional communication. ${ }^{2}$ Failure to document appropriately can negatively affect patient outcomes; as such, it is the responsibility of the individual provider and the system in which he or she works to ensure that documentation is carried out effectively. ${ }^{3}$

Several professional pharmacy organizations have published guidelines outlining the components of effective documentation in the health record. ${ }^{1,3-5}$ The Canadian Society of Hospital Pharmacists (CSHP), in its "Documentation of Pharmacists' Activities in the Health Record: Guidelines"3 and accompanying "Sample Tool to Evaluate Pharmacist's Skills for Documentation in the Health Record", ${ }^{6}$ has provided extensive criteria for effective documentation. With a special focus on pharmacists reporting data that support the pharmacotherapeutic assessment and plan, CSHP has provided a detailed framework for written communication by pharmacists in the health record.

Assessment of pharmacist competency in documentation allows for the identification of deficiencies that may impede delivery of optimal patient care. ${ }^{7}$ Although the CSHP sample tool $^{6}$ provides a thorough list of essential elements, it does not provide a means for assessing pharmacists' competency. A number of scales and rubrics are available for assessing competency, including the Likert scale, the Dreyfus and Dreyfus scale, the Stages of Learning Outcomes (SOLO), and Bloom's taxonomy. ${ }^{8-12}$ Each rubric, with the exception of the Likert scale, clearly defines stages of competency using unique sets of graduated scores.

High-quality documentation paves the way for effective and accurate communication within the health care team and prevents unnecessary duplication of work. Currently, the pharmacy department of the Regina Qu'Appelle Health Region (RQHR) does not assess the quality of pharmacist documentation in the patient health record through a formal, standardized evaluation process. The purpose of this study was to assess pharmacists' competency in the skill of health record documentation and to characterize the frequency and clinical content of these notes.

The primary objective was to determine the mean level of pharmacist competency in 18 elements of documentation using an assessment tool specifically designed for this study. The secondary objectives were to quantify the number of episodes of pharmacist documentation in the health record during predefined clinical shifts; to determine whether there was a difference in the number of episodes of documentation for pharmacists practising on different types of ward (multidisciplinary rounding wards versus non-rounding wards); to characterize the clinical activities for which pharmacists documented notes in the health record; and to quantify the mean level of competency in pharmacist documentation overall and according to years of hospital experience, additional clinical training, and note type.

\section{METHODS}

This study was approved by the RQHR Research Ethics Board as study number REB-15-03. Pharmacists at 2 tertiary care centres and 1 rehabilitation centre in the RQHR were eligible to participate on days when they were working as decentralized clinical pharmacists. Within the health region, clinical pharmacists work on the following patient care units: emergency, palliative care, oncology, cardiology, general surgery, internal medicine, intensive care, neonatal intensive care, pediatrics, long-term care, and rehabilitation. Pharmacists not scheduled to work a clinical shift during the study period and those employed as relief pharmacists or pharmacy residents were excluded, as were the study investigators.

Data collection occurred from February 17 through April 3, 2015, inclusive. Each pharmacist was assigned a specific data collection period according to his or her scheduled clinical shifts. The data collection period was rescheduled if required because of illness or schedule changes. Whenever possible, data collection 
was performed when a pharmacist was scheduled for consecutive shifts on the same patient care unit.

The principal investigator (B.B.) confirmed the data collection period with each pharmacist by e-mail 1 week before the scheduled start date, and provided a link to an online slide show outlining details of the study 3 to 5 days before the start of the data collection period. Pharmacists were contacted at the beginning of their individual data collection periods to review study expectations. During the data collection period, pharmacists were instructed to document their clinical activities in the paper-based health care record as per standard practices for pharmacists within the health region. Pharmacists were instructed to scan every documentation note and submit the scanned documents to the principal investigator by e-mail. To maintain patient confidentiality, the pharmacists de-identified the chart notes before submitting them to the investigators. Pharmacists who did not submit any notes were contacted to troubleshoot potential clinical or technical issues.

\section{Assessment Tool}

The CSHP "Sample Tool to Evaluate Pharmacist's Skills for Documentation in the Health Record" was adapted for use in this study. ${ }^{3,6}$ The study assessment tool included 18 of the 23 elements listed in the CSHP tool. Four of these elements were scored as "yes" or "no", whereas Bloom's taxonomy rubric was applied to the remaining 14 elements, with levels of "know", "comprehend", and "apply" (see Appendix 1, available at www.cjhponline.ca/index.php/cjhp/issue/view/124/showToc). Bloom's taxonomy was selected because it is currently used by the RQHR accredited pharmacy residency program. The competency descriptors for each element were drafted by the principal investigator and subsequently revised by all of the co-investigators. The co-investigators also conducted an internal audit of the assessment process, which entailed independent application of the tool to 3 separate pharmacist health record documentation notes. Co-investigator scores were compared with the principal investigator's results to unify scoring by consensus. Modifications in the assessment tool were made to address major discordances in assessment during the internal audit. After the initial internal audit and modifications to the tool, a further 3 documentation notes were assessed by each project co-investigator as a validation exercise to ensure consistency in use of the tool.

For the duration of the study, the principal investigator used the tool to complete all assessments of pharmacist notes. Every fifth note was internally audited by a single co-investigator (R.S.) until an acceptable level of agreement was attained (25\% difference or less). When more than $25 \%$ discordance was found in assessment of a note, the principal investigator and co-investigator discussed their scoring differences; if agreement was not reached, 2 more co-investigators (J.B., L.A.) assessed the note for discrepancies, and a score was obtained by group consensus.
Each note was classified by the principal investigator into 1 of 7 categories: pharmacokinetics, patient education, medication reconciliation, clarification, drug-related problem, clinical monitoring, and other.

\section{Data Analysis}

There are 17 clinical pharmacist shifts per day in the RQHR, and pharmacists in the health region previously estimated that they write about 4 notes per day. Based on a 95\% confidence interval, $5 \%$ margin of error, and response distribution of $75 \%$, analysis of 5 notes written by each of the 42 eligible pharmacists would be needed to achieve the calculated sample size of 205. As such, a maximum of 5 notes from each pharmacist were randomly selected for competency analysis using a computer-generated set of numbers from www.random.org. Level of competency was assessed by scoring 18 elements of documentation in each note. For the 4 elements scored as "yes" or "no", "yes" was given a score of 3 and "no" was given a score of 0 . For the remaining 14 elements, the following scores were assigned for each element of the rubric: $0=$ missing from note, $1=$ know, $2=$ comprehend, $3=$ apply, not applicable $=$ not included in scoring.

An aggregate note score was created for each pharmacist (the mean note score) and, where applicable, by pharmacist and note type. The distribution of continuous variables was evaluated and found to be normal, so means and standard deviations (SDs) were used to describe the data. Categorical data were described with frequency distributions. An independent $t$ test was used to compare the number of episodes of documentation between wards where pharmacists were involved in multidisciplinary care rounds and wards without such rounds, as well as to compare the level of competency according to pharmacists' level of training. One-way analysis of variance was used to determine whether there was a difference in pharmacist competency according to note type or pharmacist experience.

\section{RESULTS}

Thirty-five (83\%) of the 42 eligible pharmacists met the inclusion criteria (Table 1). A total of 142 notes were collected during the 6-week study period. The number of notes collected per pharmacist varied in relation to number of collection days (Table 2). A mean of 4.0 (SD 1.2) notes were collected per pharmacist during their respective data collection periods, which resulted in a mean of 0.9 (SD 0.6) notes per pharmacist per day. Pharmacists on rounding wards collected a mean of 3.6 (SD 1.6) notes, whereas pharmacists on non-rounding wards collected a mean of 3.9 (SD 1.2) notes. There were no significant differences in the number of notes collected by ward type $(t=0.60, \mathrm{df}=28$, $p=0.56$ )

As per study protocol, a maximum of 5 notes per pharmacist were assessed for competency, which resulted in a sample of 115 
notes ( $81 \%$ of the 142 notes submitted). These notes were created by 29 of the 35 pharmacists ( 6 of the pharmacists did not submit any notes). The most common types of notes were for drugrelated problems (50 [43\%]), pharmacokinetics (25 [22\%]), and patient education (19 [17\%]) (Table 3). Twenty-three of the 115 notes were audited by a co-investigator, and 7 (30\%) of these had greater than $25 \%$ discrepancy. Three of these 7 notes required decision via group consensus with 2 additional reviewers, whereas the other 4 were reconciled after discussion between the principal investigator and the co-investigator.

Each of the 18 elements of documentation was assessed for all 115 notes. All but one note (99\%) included the date, but only 66 notes (57\%) included the time. Pharmacist identification was present in 72 notes $(63 \%)$, and contact information was provided in 49 notes (43\%). Figure 1 shows the level of competency achieved for the 14 elements of documentation assessed by Bloom's taxonomy. Competency scores were highest for the following elements: diplomatic tone (mean 2.93, SD 0.37), conciseness (mean 2.83, SD 0.44), and clarity (mean 2.50, $\mathrm{SD}$ 0.61). The lowest scores were observed for monitoring (mean 0.69 , SD 0.81), title (mean 1.62, SD 0.66), medication list (mean $1.71, \mathrm{SD} 0.90$ ), and drug-related problem statements (mean 1.82, SD 0.96). Monitoring was the element most frequently missing from notes.

The mean overall competency score for the study cohort was 2.2 (SD 0.3) out of a maximum possible score of 3. There were no statistically significant differences in scores obtained by pharmacists with varied years of experience $\left(F_{(2,26)}=0.396\right.$, $p=0.68)$ or additional clinical training $(t=1.45, \mathrm{df}=27$, $p=0.16$ ) (Table 4). Furthermore, there were no statistically significant differences in competency score by note type $\left(F_{(5,65)}=1.62, p=0.17\right)($ Table 5$)$.

\section{DISCUSSION}

This study assessed pharmacists' levels of competency for 18 elements of chart note documentation using a documentation assessment tool. The tool was unique in that a competency rubric in the form of Bloom's taxonomy was applied to 14 of the core components of CSHP's "Sample Tool to Evaluate Pharmacist's Skills for Documentation in the Health Record". ${ }^{6}$ The adaptation provided examples of descriptive anchor points to assist in the differentiation of levels of competency. Herritt and others ${ }^{13}$ used a modified version of the CSHP tool to identify the presence or absence of the core elements; however, they did not assess the levels of competency in addressing each element. Although the tool used in this study was not validated, and there were identified discrepancies in the auditing process, the investigators demonstrated the consistency of its interpretation, which increased the reliability of assessments. However, because this study was prospective and pharmacists were aware of their participation, the Hawthorne effect dictates that the results may be more positive

\section{Table 1. Participant Characteristics}

\begin{tabular}{lc} 
Characteristic & $\begin{array}{r}\text { No. }(\%) \text { of Pharmacists } \\
(\boldsymbol{n}=\mathbf{3 5})\end{array}$ \\
\hline Hospital experience & $10(29)$ \\
$<2$ years & $4(11)$ \\
$2-5$ years & $21(60)$ \\
$>5$ years & \\
\hline Postbaccalaureate clinical training & $14(40)$ \\
Residency or PharmD & $21(60)$ \\
No additional training & \\
\hline
\end{tabular}

Table 2. Number of Notes Collected*

\begin{tabular}{lccc}
$\begin{array}{l}\text { Duration of } \\
\text { Collection Period }\end{array}$ & $\begin{array}{c}\text { No. of Notes } \\
\text { Collected }\end{array}$ & $\begin{array}{c}\text { No. }(\%) \text { of Pharmacists } \\
(\boldsymbol{n}=35)\end{array}$ \\
\hline 3 days & 0 & 1 & $(3)$ \\
& $1-5$ & 1 & $(3)$ \\
& $>5$ & 0 & \\
\hline 4 days & 0 & 2 & $(6)$ \\
& $1-5$ & 2 & $(6)$ \\
& $>5$ & 2 & $(6)$ \\
\hline 5 days & 0 & 3 & $(9)$ \\
& $1-5$ & $14(40)$ \\
& $>5$ & $10(29)$
\end{tabular}

${ }^{*}$ An individual pharmacist's notes were collected on 3 days, on 4 days, or on 5 days. The data values reported here are mutually exclusive.

Table 3. Classification of Notes Documented by Pharmacists

\begin{tabular}{lc} 
Note Type & $\begin{array}{c}\text { No. }(\%) \text { of Notes } \\
(\boldsymbol{n}=\mathbf{1 1 5})\end{array}$ \\
\hline Drug-related problem & $50(43)$ \\
Pharmacokinetics & $25(22)$ \\
Patient education & $19(17)$ \\
Medication reconciliation & $9(8)$ \\
Clarification & $5(4)$ \\
Clinical monitoring & 0 \\
Other* & $7(6)$
\end{tabular}

*Medication availability (special access, nonformulary), medication coverage, location of uncommonly used products.

Table 4. Competency Score According to Years of Hospital Experience and Additional Clinical Training

\begin{tabular}{|c|c|c|}
\hline $\begin{array}{l}\text { Experience/ } \\
\text { Training }\end{array}$ & $\begin{array}{l}\text { Competency Score } \\
\text { (Mean } \pm \text { SD) }\end{array}$ & $\begin{array}{l}\text { No. of Notes per } \\
\text { Pharmacist per Day } \\
\text { (Mean } \pm \text { SD) }\end{array}$ \\
\hline \multicolumn{3}{|c|}{ Hospital experience* } \\
\hline$<2$ years $(n=10)$ & $2.2 \pm 0.3$ & $0.9 \pm 0.5$ \\
\hline $2-5$ years $(n=4)$ & $2.3 \pm 0.2$ & $0.7 \pm 0.5$ \\
\hline$>5$ years $(n=21)$ & $2.1 \pm 0.3$ & $0.8 \pm 0.7$ \\
\hline \multicolumn{3}{|c|}{ Postbaccelaurate clinical trainingt } \\
\hline $\begin{array}{l}\text { Residency/ } \\
\text { Pharm D }(n=14)\end{array}$ & $2.3 \pm 0.3$ & $0.9 \pm 0.8$ \\
\hline None $(n=21)$ & $2.1 \pm 0.2$ & $0.8 \pm 0.5$ \\
\hline Overall & $2.2 \pm 0.3$ & $0.9 \pm 0.6$ \\
\hline
\end{tabular}




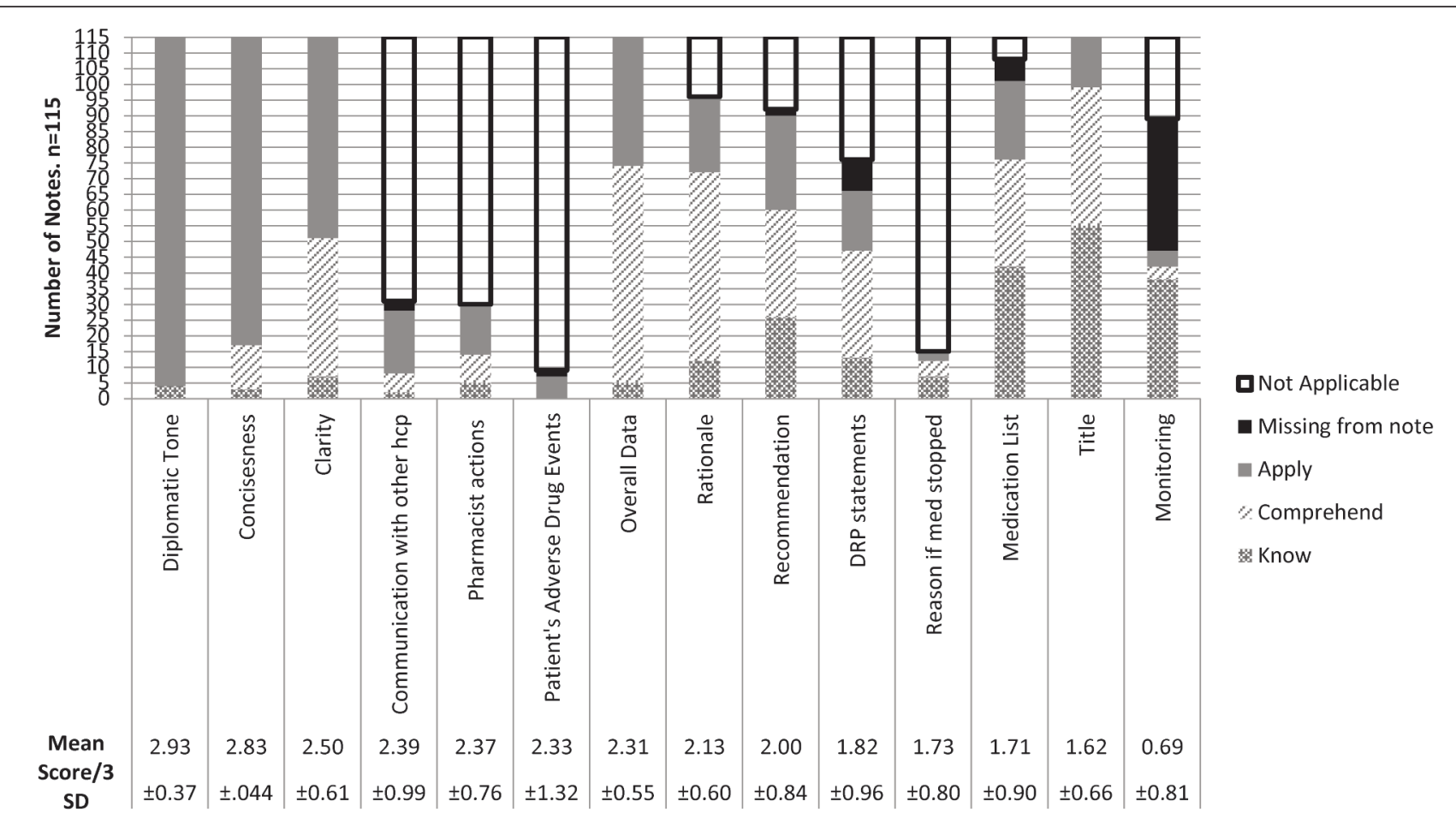

Figure 1. Level of competency for 14 elements of documentation assessed by Bloom's taxonomy.

than would have been the case if pharmacists had not been aware of their participation.

The majority of clinical pharmacists within the health region were eligible for participation in this study, and those included were representative of the pharmacist population. The sample included a mix of both baccalaureate-trained (40\%) and additionally trained (residency and/or PharmD) pharmacists (60\%), with a diversity of clinical experience, including more than 5 years of hospital experience for $60 \%$ of the pharmacists. This sample is comparable to the Canadian situation, where $43 \%$ of hospital pharmacists have baccalaureate training and $73 \%$ of Canadian hospital pharmacists have more than 5 years of experience. ${ }^{14}$ The clinical activities most frequently documented by pharmacists in this study included drug-related problems, pharmacokinetics, and patient education. In comparison, Herritt

\section{Table 5. Competency Score According to Note Type}

\begin{tabular}{lcc} 
Note Type* & No. of Notes & Score (Mean \pm SD) $\dagger$ \\
\hline Drug-related problems & 50 & $2.1 \pm 0.3$ \\
Pharmacokinetics & 25 & $2.2 \pm 0.3$ \\
Patient education & 19 & $2.4 \pm 0.2$ \\
Medication reconciliation & 9 & $2.2 \pm 0.3$ \\
Clarification & 5 & $2.1 \pm 0.4$ \\
Other & 7 & $2.1 \pm 0.4$
\end{tabular}

${ }^{\star} F_{(5,65)}=1.62, p=0.17$.

†Aggregated by pharmacist and type of note. and others ${ }^{13}$ reported that the clinical activities most commonly documented by pharmacists included clarifications, order sets, clinical progress notes, and pharmacist suggestions. These differences in note-type categories may be a result of differences in study terminology. Regardless, caution may be necessary in the extrapolation of our findings to other sites.

Within the study cohort, the mean competency of documentation across all pharmacist notes was 2.2 (SD 0.3), with no statistically significant differences among different types of notes. Documentation competency was highest for patient education notes and lowest for clarification and drug-related problem notes. Although this trend suggests a lower level of pharmacist competency in the skill of documenting drug-related problems, it did not reach statistical significance, and other factors, such as differences in the required information for each type of note, may have affected this finding.

Pharmacists' notes were concise and clear, and had a diplomatic tone, as displayed by the higher mean scores for these elements. Additionally, higher scores were achieved for the documentation of interactions with other health care providers and description of pharmacists' own activities. However, pharmacists inconsistently included the basic requirements of time, identification, and contact information in their health record documentation notes. This finding is similar to the results of Herritt and others, ${ }^{13}$ who reported that date/time, title, and pharmacist identification were missing from $82 \%, 58 \%$, and $36 \%$ of notes, 
respectively. These basics of health record documentation require little skill. As such, the relatively poor compliance with these required elements should be easily addressed through feedback and reminders of the required core elements of documentation.

Although these findings demonstrate both strengths and opportunities for improvement in the documentation process, a greater challenge within the local health region may be the frequency with which pharmacists perform documentation. On average, less than one note per pharmacist per day was provided for study assessment. The number of submissions ranged from 0 notes ( 6 pharmacists) to 13 notes ( 1 pharmacist). According to data from the RQHR clinical intervention tracking tool, pharmacists perform a total of approximately 57 clinical interventions per day, which is about 5 interventions per pharmacist per day. This suggests that less than $20 \%$ of interventions are being documented in the patient health record. This finding is lower than reported in the literature: Herritt and others ${ }^{13}$ found that pharmacists documented $31 \%$ of their interventions, and Gordon and others ${ }^{15}$ found an average rate of 1.5 notes per pharmacist per day.

Given the small sample size in this study, the 6 pharmacists who collected no notes skewed the mean daily data collection results. Among these pharmacists, 5 had more than 5 years of hospital experience, 1 had less than 2 years of hospital experience, and 2 had additional clinical training. Therefore, it appears that neither greater clinical experience nor additional clinical training was sufficient to ensure that notes would be written. It was beyond the scope of this study to determine why pharmacists did not document at the frequency expected for the number of clinical interventions performed. However, the pharmacists who submitted no notes mentioned the following reasons for lack of health record documentation: drug-related problems were resolved through face-to-face discussion with other health care practitioners or before the medication was entered in the medication management system, and perception of documentation as not being an effective tool for resolving drug-related problems (related to a perception that pharmacist notes are largely not read by physicians). This apparent lack of understanding of the clinical importance of and legal obligations to document in the permanent patient health record accords with previously reported reasons for lack of documentation, which have included personal practice, workload, or lack of clarity about why documentation is required, what is required to be documented, or where documentation should occur. ${ }^{13,15-17}$

Verbal communication is often insufficient to ensure continuity of care, and failure to document in the permanent patient health record may impair delivery of optimal patient care. ${ }^{3}$ According to the Canadian Health Services Research Foundation, "information is the common thread linking care from one provider to another and from one health event to another." ${ }^{18}$ Additionally, documentation is a required standard activity for all health care providers to ensure that all elements of care, including interactions with patients, discussions among health care providers, interventions carried out (or disagreed upon), and monitoring plans, are included in the patient's permanent health record, which in turn ensures that all relevant clinical information is available for all health care providers making clinical decisions in patient care. ${ }^{19}$

This study had limitations that may affect the interpretation and application of the results. The tool that we used has not been previously validated. We applied Bloom's taxonomy to the elements identified by CSHP, which was a unique approach. However, the scoring rubric assessed certain components multiple times (e.g., relevance of documented information was assessed as part of both "conciseness" and "overall data/information") and the definitions of "apply" for certain elements (e.g., title) seemed too specific, preventing many participants from achieving this level. Through the study, the investigators gained insight into these limitations of the tool and noted potential areas of improvement. Pharmacists were aware that they were participating in the study and were responsible for submitting their notes. They may have selected notes for submission according to perceived quality and may have changed their documentation practices in response to being assessed. On the basis of staff pharmacist reports and clinical intervention data, investigators thought that it would be relatively easy to obtain 5 notes from each pharmacist over a 5-day clinical period; however, for several pharmacists, we were unable to include 5 data-collection days. Finally, the study was a snapshot in time, and the study period may not have been long enough to gather the true picture of pharmacists' documentation practices in the RQHR.

\section{CONCLUSION}

Although the overall frequency of chart note documentation by pharmacists was lower than anticipated, this study demonstrated an acceptable level of pharmacist competency in the skill of health record documentation. The basics of health record documentation (time, identification, and contact information) were identified as areas that are readily amenable to improvement.

\section{References}

1. American Society of Health-System Pharmacists. ASHP guidelines on documenting pharmaceutical care in patient medical records. Am J Health Syst Pharm. 2003;60(7):705-7.

2. A national interprofessional competency framework. Vancouver (BC): Canadian Interprofessional Health Collaborative; 2010 [cited 2014 Sep 30]. Available from: www.cihc.ca/files/CIHC_IPCompetencies_Feb1210.pdf

3. Documentation of pharmacists' activities in the health record: guidelines. Ottawa (ON): Canadian Society of Hospital Pharmacists; 2013 [cited 2014 Sep]. Available from: https://cshp.ca/system/files/Publications/Guidelines/ Guidelines_Documentation\%20(2013).pdf. Membership required to access content.

4. Currie JD, Doucette WR, Kuhle J, Sobotka J, Miller WA, McDonough RP, et al. Identification of essential elements in the documentation of pharmacistprovided care. J Am Pharm Assoc. 2003;43(1):41-9. 
5. Standards of practice for clinical pharmacists. Washington (DC): American College of Clinical Pharmacy; 2014 Mar [cited 2015 Oct]. Available from: www.accp.com/standards

6. Appendix B: Sample tool to evaluate pharmacist's skills for documentation in the health record. In: Documentation of pharmacists' activities in the health record: guidelines. Ottawa (ON): Canadian Society of Hospital Pharmacists; 2013 [cited 2014 Sep]. Available from: https://cshp.ca/ system/files/Publications/Guidelines/Guidelines_Documentation_ AppendixB\%20(2013).pdf. Membership required to access content.

7. Summers BG, Woods WS, editors. Competency assessment: a practical guide to the joint commission standards. 3rd ed. Marblehead (MA): HCPro; 2008.

8. van Alphen A, Halfens R, Hasman A, Imbos T. Likert or Rasch? Nothing is more applicable than good theory. J Adv Nurs. 1994;20(1):196-201.

9. Lester S. Novice to expert: the Dreyfus model of skill acquisition. London (UK): Stan Lester Developments; 2005 [cited 2014 Nov]. Available from: http://devmts.org.uk/dreyfus.pdf

10. Dreyfus HDS. Mind over machine: the power of human intuition and expertise in the era of the computer. New York (NY): Free Press; 1986.

11. Biggs JB, Collis KF, Edward AJ. Evaluating the quality of learning: the SOLO taxonomy (Structure of the Observed Learning Outcome). New York (NY): Academic Press, Inc; 1982.

12. Krathwohl DR, Bloom BS, Masia BB. Taxonomy of educational objectives: Book 2 affective domain. 2nd ed. New York (NY): Longman; 1964.

13. Herritt L, MacInnis M, Grimm N, Lee R, MacLean D, MacNeil T, et al. Analysis of current pharmacist documentation practices in a tertiary care hospital [abstract]. Can J Hosp Pharm. 2014;67(4):318.

14. Hall K, Bussières JF. Chapter J: Front-line pharmacists survey. In: Hospital pharmacy in Canada 2013/2014 report. Hospital Pharmacy in Canada Editorial Board; 2014 [cited 2015 Jun 3]. p. 120-33. Available from: www. lillyhospitalsurvey.ca/hpc2/content/rep_2015_toc.asp

15. Gordon W, Malyuk D, Taki J. Use of health-record abstracting to document pharmaceutical care activities. Can J Hosp Pharm. 2000;53(3):199-205.

16. Makowsky MJ, Schindel TT, Rosenthal M, Campbell K, Tsuyuki RT, Madill HM. Collaboration between pharmacists, physicians and nurse practitioners: a qualitative investigation of working relationships in the inpatient medical setting. J Interprof Care. 2009;23(2):169-84.

17. Kennie N, Farrell B, Dolovich L. Demonstrating value, documenting care: lessons learned about writing comprehensive patient medication assessments in the IMPACT project. Part I: getting started with documenting medication assessments. Can Pharm J. 2008;141(2):114-9.
18. Reid R, Haggerty J, McKendry R. Defusing the confusion: concepts and measures of continuity of healthcare. Ottawa $(\mathrm{ON})$ : Canadian Health Services Research Foundation; 2002 [cited 2014 Dec 10]. Available from: www.hpm.org/Downloads/Bellagio/Articles/Continuity/cr_contcare_e.pdf

19. Angaran DM. Quality assurance to quality improvement: measuring and monitoring pharmaceutical care. Am J Hosp Pharm. 1991;48(9):1901-7.

Brittany Baranski, BSC BSP, ACPR, was, at the time of this project, with the Regina Qu'Appelle Health Region, Regina, Saskatchewan. She is now with the Saskatoon Co-Op, Saskatoon, Saskatchewan.

Jennifer Bolt, BSCPharm, ACPR, PharmD, was, at the time of this project, with the Regina Qu'Appelle Health Region, Regina, Saskatchewan. She is now with the Interior Health Authority, Kelowna, British Columbia.

Lori Albers, BSP, ACPR, is with the Regina Qu'Appelle Health Region, Regina, Saskatchewan.

Rabiah Siddiqui, BScPhm, ACPR, is with the Regina Qu'Appelle Health Region, Regina, Saskatchewan.

Ali Bell, MSc, is with the Regina Qu'Appelle Health Region, Regina, Saskatchewan.

William Semchuk, MSc, PharmD, FCSHP, is with the Regina Qu'Appelle Health Region, Regina, Saskatchewan.

Competing interests: None declared.

Address correspondence to:

Dr Jennifer Bolt

Interior Health Authority

2255 Ethel Street

Kelowna BC V1Y $2 Z 9$

e-mail: jennifer.bolt@interiorhealth.ca

Funding: None received. 